\title{
EL SISTEMA BANCARIO ESPAÑOL DEL SIGLO XIX: \\ ¿UNA ESTRUCTURA DUAL? \\ NUEVOS PLANTEAMIENTOS \\ $Y$ NUEVAS PROPUESTAS
}

JOSE RAMON GARCIA LOPEZ

Universidad de Oviedo

\section{Introducción}

El título original de este trabajo, según figuraba en el programa del Curso de Verano que la Universidad de Oviedo dedicó el pasado año a la conmemoración del veinte aniversario de la publicación de la obra España bace un siglo: una economia dual, del profesor Sánchez-Albornoz, era el de «Bancos y Banqueros en la España del siglo XIX», pero para expresar de una manera más gráfica mi modesto homenaje particular al autor y a su obra, me voy a permitir alterarlo tomando como método de análisis, o mejor dicho, de ruptura, el lema de la obra que es objeto de conmemoración.

Así, pues, el planteamiento inicial podría ser formulado en los siguientes términos: ¿cabe asignar al sistema bancario español del siglo xix una estructura dual como la que el profesor Sánchez-Albornoz muestra para el conjunto de la economía española? Y si es así, ¿ pueden deducirse para él las mismas conclusiones? Estos son los dos temas que me propongo desarrollar.

El sistema bancario español del siglo xIx estuvo formado por dos tipos de instituciones: las que giraban bajo firma individual o como sociedades colectivas o comanditarias (banqueros, comerciantes-banqueros, casas de banca), y las constituidas con forma de sociedad anónima (bancos y sociedades de crédito). Esto supone, indudablemente, una dualidad. Ahora bien, ¿se corresponde esta dualidad con la aplicada por el profesor Sánchez-Albornoz a la agricultura o a la economía española en general, en el sentido de la existencia conjunta de modelos antiguos y modernos? Aparentemente, sí: desde luego, banqueros y comerciantes-banqueros ya los había habido desde siglos atrás; eran, por tanto, empresas de tipo antiguo, mientras que los bancos-sociedad anónima, aun no siendo propiamente un invento del siglo xix, sí eran formas modernas.

La discrepancia surge, a mi juicio, cuando se intenta adscribir a los términos antiguo y moderno las características que descalifican a uno y sacralizan a otro. Porque si la dualidad es indiscutible en cuanto a las formas que 
adoptan, ya lo es menos si analizamos sus técnicas, su estructura organizativa y funcional y sus resultados, y son más bien estos criterios los que deben ser utilizados para calificar a un modelo de antiguo - anticuado- o moderno. Y si aceptamos que el modo antiguo o tradicional implica poca producción y baja productividad, con las consiguientes secuelas de escaseces en la oferta y elevados costos, ¿puede esto aplicarse a las formas antiguas de empresas bancarias, banqueros y comerciantes banqueros? Esta es una cuestión a resolver.

Por otra parte, el otro tipo de empresas bancarias, las modernas, los bancos y sociedades de crédito, ¿cumplieron con la función requerida por una economía en vías de industrialización? ¿Dio respuesta la modernización del sistema bancario (entendida como la formación de entidades con forma de sociedad anónima) a lo que la sociedad española del siglo xix demandó para su desenvolvimiento económico? Esta es otra cuestión a resolver.

Ambas preguntas convergen en una misma respuesta que las explica: todos los estudios coinciden en señalar que el sistema bancario español del siglo xIX (entendiendo por tal sistema sólo el conjunto de bancos y sociedades de crédito) no dio los resultados esperados y dejó mucho que desear en número, distribución espacial y asignación de recursos. Entonces, ante el fracaso de ese sistema ${ }^{1} \mathrm{o}$, dicho de otro modo, ante el fracaso de la modernización del sistema bancario, surge inevitablemente la pregunta de cómo pudo resolverse esta carencia, porque el colapso del sistema bancario habría provocado el caos total en la actividad económica, y, sin embargo, no fue así. En mi opinión, la respuesta a este interrogante es que la misma carencia de bancos dio lugar al crecimiento espontáneo de un sistema alternativo que fue atendiendo progresivamente necesidades de mediación financiera deficientemente cubiertas. De este modo, el fracaso de la banca moderna permitió y forzó el crecimiento y difusión de lo que tendríamos que llamar banca tradicional, es decir, los banqueros y comerciantes-banqueros, que con su propia dinámica llenaron un espacio vacío, ocupándose de realizar las diversas funciones y servicios bancarios requeridos por la sociedad española de su tiempo.

\footnotetext{
1 Hablar de fracaso en historia económica comporta indiscutibles evocaciones al profesor Nadal. En este caso, no sólo por el término, sino porque hay, o, mejor dicho, pretende el autor de este trabajo que las haya, otras analogías. De igual modo que el profesor Nadal estima que es necesario repensar los planteamientos de su obra El fracaso de la Revolución Industrial en España, no porque no haya habido fracaso, sino porque basar el análisis casi exclusivamente en el algodón y en la siderurgia resulta una deformación de la realidad, al dejar fuera una serie de actividades que además de «contribuir al producto industrial han adoptado, en muchas ocasiones, las técnicas de producción y las formas de organización modernas" (Nadal, 1987, p. 23), así también el fracaso del sistema bancario español debe reducirse al fracaso de un sector del mismo, el de los bancos con forma de sociedad anónima.
} 


\section{Los bancos y sociedades de crédito}

Demos, en primer lugar, un rápido repaso a lo que constituyó el conjunto de bancos y sociedades de crédito con forma de sociedad anónima, que impropiamente ha sido identificado como el sistema bancario español del siglo xix.

Hasta 1844 existió un solo banco en España, el de San Carlos (desde 1829 denominado de San Fernando), que, además, centraba sus actividades en el servicio al Estado, con descuido del sector privado ${ }^{2}$. En 1844 se fundaron los bancos de Isabel II y de Barcelona, y dos años más tarde se abría en Cádiz una sucursal del primero; constituyéndose ese mismo año la Caja de Descuentos de Zaragoza y la Sociedad Valenciana de Crédito y Fomento. Fusionados en 1847 los bancos de Isabel II y de San Fernando, la sucursal de Cádiz pasó a funcionar con autonomía, y otras dos instituciones vinieron a unirse a las existentes, aunque con efímera vida: el Banco de la Unión y el Banco de Fomento y Ultramar ${ }^{3}$. En resumen, en los comienzos de los años cincuenta el número de bancos operantes en España se reducía a cinco o seis, y obliga a pensar en lo forzado que resulta calificar a tan exiguo número de «sistema». Parece claro que en modo alguno pudieron haber cubierto unos mínimos servicios de mediación financiera, por grande que fuera el atraso económico español, por lo que necesariamente, hasta estos años al menos, hay que recurrir a los banqueros tradicionales si queremos explicar con un mínimo rigor la estructura bancaria española.

El año 1856 marca el comienzo de lo que podría denominarse el intento de modernización del sistema bancario español, con la promulgación de las leyes de Bancos de Emisión y Sociedades de Crédito, que permitieron constituir en un período de diez años nada menos que 18 bancos y 35 sociedades de crédito. Sin embargo, apenas había terminado esta década expansiva cuando empezó una fase de signo contrario: a partir de la crisis de 1865-66, graves dificultades obligaron a muchas de esas entidades a cerrar, continuando otras una lánguida marcha. En 1873 quedaban 33 entidades bancarias por acciones, algunas de ellas en situación precaria. Habían pasado ya tres cuartos de siglo, y la modernización apenas había traído más que disgustos.

Pero no fue esta fecha el final de las desdichas de los bancos-sociedad anónima. Una nueva oleada de constituciones tuvo lugar en 1881-82, creándose 42 bancos ( 28 de ellos en Cataluña) ${ }^{4}$, de los que menos de una docena verían terminar el siglo. En la última década del siglo, hacia 1892, el número

\footnotetext{
${ }^{2}$ G. Tortella (1975), p. 33.

${ }^{3}$ G. Tortella (1975), p. 35.

+ P. Tedde (1974), p. 271.
} 
de bancos privados en España era de $35^{5}$, a los que habría que añadir las

58 sucursales que, por aquellos años, tenía el Banco de España ${ }^{6}$. La cifra, para una techá tán avanzada, sìgue mostrando una apariencia sospechosamente baja.

Este es, a grandes rasgos, el balance numérico del conjunto de bancos y sociedades de crédito con forma de sociedad anónima, fruto del proceso de modernización bancaria, que ha sido calificado de lento y tardío, y que además de presentar un escaso número de establecimientos, al hacerlo con una cierta concentración en los dos polos de Madrid y Barcelona, acentuaba aún más sus deficiencias. En definitiva, el sistema bancario moderno no ha gozado de la aprobación de los historiadores, acusándosele, además, de no haber canalizado sus recursos adecuadamente.

\section{Los banqueros y comerciantes banqueros}

Reivindicar el papel fundamental desempeñado por los banqueros como componente esencial del sistema bancario español de la primera mitad del siglo xIx no debiera resultar problemático. La existencia de un solo banco hasta 1844 y los cuatro o cinco que se abrieron en los años siguientes obliga a admitir su presencia como indispensable. Se conocen, además, bastantes nombres de banqueros, algunos incluso con tintes novelescos, que facilitan esta explicación?. Parece, pues, indiscutible que durante la primera mitad del siglo fue el colectivo de banqueros quien llevó el peso de la función bancaria.

Más difícil se presenta asignar a los banqueros un papel tan importante y tan claro dentro del sistema bancario español para la segunda mitad del siglo xIx. Y ello porque se nos habla de la desaparición progresiva de los banqueros particulares y de la constitución de numerosas sociedades anónimas bancarias. Intentaré rebatir la pretendida desaparición de los banqueros más adelante, y por lo que se refiere a la constitución de bancos, debemos tener presente que constitución no equivale a pervivencia: en el cuadro 1 se puede ver quiénes realizaban, en realidad, la función bancaria en los años setenta, después del descalabro de gran parte de los bancos constituidos entre 1856 y 1864. La dificultad, entonces, estriba más bien en que estos banqueros de la segunda mitad del siglo xix ya no eran la haute banque, los grandes

5 P. Tedde (1974), p. 330.

R. Anes (1974), p. 134.

7 P. Tedde (1983), p. 311 , reproduce de diversas fuentes una relación de banqueros establecidos en Madrid en 1808, y A. Otazu (1988) cita a lo largo de su obra importantes casas de banca de Madrid, así como banqueros tan relevantes como Remisa, Safont, Bertrán de Lis, Weisweiller, Carriquiri, que operaban antes de mitad de siglo. 
banqueros que prestaban al Estado - aunque también lo hacían-, sino espe-

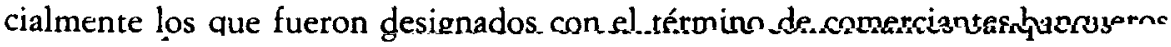
por el Ministerio de Hacienda en $1870^{8}$, y que por no estar sometidos a ninguna obligación de dar publicidad a sus balances y cuentas de resultados han quedado al margen de las estadísticas sin otra posibilidad de ser estudiados que la de acudir a sus propios libros de cuentas.

\section{CUADRO 1}

\section{Corresponsales del Banco de Oviedo (Año 1871)}

Alicante: Salvette, Harmsen y Cía.

Barcelona: Vidal Quadras Hnos.

Bilbuo: Andrés de Isasi.

Burgos: Crisanto Espiga.

Cádiz: José S. Mendaro, Benito Picardo.

Gijón: Casimiro Domínguez Gil.

Granada: Hijos de Francisco Agrela.

La Coruña: Herze y Alsina.

León: Jover y Menéndez.

Lugo: Ramón Roca Soler.

Málaga: A. Sans y Cía., Banco de Málaga.

Madrid: Fabra, Ponte y Cía., León Ad.
Palencia: Tadeo Ortiz.

Pamplona: Vda. de Ribert e Hijos.

San Sebastián: Juan Gucheille.

Santander: Lucas Zúñiga, José M. Aguirre, Banco de Santander.

Santiago: Manuel Pérez Sáenz.

Sevilla: Gonzalo Segovia.

Tarragona: Banco de Tarragona.

Valencia: Caruana Hnos. y Cía.

Valladolid: Vda. de Sigler e Hijos.

Vigo: M. Bárcena Hnos., Francisco J. Ro. dríguez.

Zaragoza: Villarroya y Castellano.

Fuente: Libro de Inventarios del Banco de Oviedo, f. 192. Se excluyen los corresponsales de los pueblos de la provincia.

¿Quiénes eran estos comerciantes-banqueros? Pues simplemente aquellos que relacionados con la actividad económica general -comerciantes, fabricantes, transportistas, consignatarios... - empezaron a realizar en pequeña escala las esenciales operaciones de banca — giro, negociación, préstamo, etc.-, primero para atender sus propias necesidades y paulatinamente para un círculo de clientes cada vez más amplio, hasta terminar especializándose e incluso abandonando la primigenia ocupación comercial e industrial. Para realizar esta «industria de banca», disponían de todo lo necesario: capital, establecimiento abierto al público, técnica comercial, amplias relaciones mercantiles

- El Decreto de 20 marzo 1870 relativo a la Contribución Industrial y de Comercio, en su tarifa $2 .^{2}$, epígrafe 22 , gravaba a los «Comerciantes-banqueros cuyo ejercicio habitual es comprar, vender y descontar por cuenta propia o ajena letras, documentos de giro y valores cotizables en la Bolsa». El término comerciantes-banqueros se mantendría hasta bien entrado nuestro siglo. 
y un sólido crédito personal, basado en una solvencia y seriedad largamente probadas. En estos cinco atributos, todos ellos esenciales en los negocios bancarios, residía su fuerza.

La conversión de comerciante en banquero o, más exactamente, la especialización en operaciones de banca, con o sin abandono de su actividad tradicional, era un proceso generalmente lento y en ocasiones imperceptible. Quizá el único hito reconocible en este proceso era la inscripción en la matrícula fiscal, a lo que se llegaba por la evidencia del crecimiento del negocio, que conducía al reconocimiento exterior oficial, al tiempo que implicaba una intención de proseguir en la actividad de banca.

Es posible que la utılización del término comerciante-banquero por el Ministerio de Hacienda nos dé la clave para explicar su contenido. La banca es, desde luego, una forma de comercio, pero la naturaleza de la mercancía sobre la que se ejerce -el dinero y el crédito- le concede un carácter especial. Tan especial que se le separa de todas las demás modalidades. Y así, a efectos fiscales, mientras otras industrias podían ejercerse conjuntamente tributando por una sola de ellas, la banca siempre fue discriminada (salvo en el breve período 1850-52), debiendo pagar la cuota de banqueros los que realizaban esas operaciones, fuese cual fuese la otra actividad con la que se simultaneaba ${ }^{9}$. Por eso, las casas de banca más pequeñas, los comerciantesbanqueros de las pequeñas localidades, solian resistirse a darse de alta como banqueros, porque implicaba el pago de una nueva cuota, y de las más altas, por lo que permanecían en cierto modo ocultos, en tanto no se producía una denuncia $o$ inspección. Esta cuestión es algo que debemos tener presente cuando tratemos del número de comerciantes-banqueros en España.

\section{Tipologia de los banqueros y comerciantes-banqueros}

El proceso por el que un comerciante se convertía en banquero revestía múltiples formas, aunque en el fondo todas ellas obedecían a un doble condicionante: la necesidad de la mediación y la aptitud para desarrollar la función requerida. Pero esta transformación condujo a varios tipos, que aquí vamos a clasificar como locales, regionales y nacionales, no porque su ámbito de relaciones se circunscribiera a esos límites, pues incluso los banqueros locales tenían en algunos casos corresponsales en el extranjero, sino por utilizar el modelo de gradación que esos términos comportan.

a) Comerciantes-banqueros locales, establecidos en pequeñas poblaciones, con comercio mixto o pequeña industria (de alimentación, transportes, mi-

9 J. R. García López (1987), p. 32. 
nas...), que actuaban como corresponsales de casas de mayor importancia, generalmente de la capital de su provincia. Atendían el cobro y pago de letras, la operación menos lucrativa de las bancarias, pero gracias a la cual realizaban sus propios pagos a sus proveedores y captaban clientes para su actividad, lo que les producían beneficios de mayor consideración. Una parte de las letras que pagaban eran las remitidas por los emigrantes de Ultramar a sus familias - las famosas remesas - que tan benéficos efectos produjeron en multitud de economías familiares. No pocos de estos banqueros locales llegaron a constituir sociedades anónimas bancarias, integrándose otros como sucursales de los grandes bancos nacionales en el período de expansión bancaria de las primeras décadas del siglo $\mathbf{x x}$.

b) Comerciantes-banqueros o casas de banca de ámbito regional, situadas en las capitales de provincia o ciudades portuarias importantes. Realizaban todas las funciones y comisiones bancarias, como la negociación y descuento de letras, giro (también sobre el extranjero, operación habitual), préstamos a particulares y a empresas (con frecuencia muy elevados), compraventa de valores (quizá la actividad más lucrativa, aunque arriesgada), cambio de moneda, etc. Llevaban también a cabo las más diversas operaciones, por ejemplo las necesarias para poner en marcha las nuevas grandes empresas, para lo que se encargaban de percibir los dividendos pasivos facilitando su financiación. $\mathrm{O}$ el arrendamiento en subasta de la recaudación del impuesto de Consumos. En fin, que ningún asunto comercial —entendido en el más amplio sentido- les era ajeno, acometiéndolo con una diligencia y profesionalidad verdaderamente encomiables. Estas casas de ámbito regional, que generalmente habían nacido por evolución de actividades comerciales o industriales, llegaban a alcanzar un volumen de operaciones de banca tan crecido que les conducía a abandonar, o al menos a separar - física o contablemente- ambos tipos de actividades.

c) Comerciantes-banqueros o casas de banca de ámbito nacional, establecidas fundamentalmente en Madrid y Barcelona. De grandes magnitudes, superaban en escala los negocios de las casas que denominamos regionales, a las que facilitaban buena parte del papel, les redescontaban efectos (con lo que aligeraban su cartera) y les proporcionaban sumas elevadas en moneda extranjera cuando excedia de las posibilidades de aquéllas. Canalizaban buena parte de las remesas de Ultramar (sin perjuicio de las que llegaban directamente a las casas regionales o locales, algunas, como por ejemplo «E. Sainz e Hijos", tenían una verdadera especialización), y financiaban mayores proyectos, algunos de gran magnitud, sindicados. Como las casas regionales, los orígenes podían estar en el comercio de mercancías, pero había también ban. 
queros exclusivamente, bien por haberse constituido así como delegados o representantes de casas extranjeras (Weisweiller y Baüer), o por haber sido creadas ex novo con capitales de varios comerciantes o banqueros puestos bajo la gestión de un técnico en banca ( P. Alfaro y Cía.»).

En cuanto a la forma que adoptaban, cabe también establecer tres figuras distintas:

i) Comerciantes-banqueros individuales.-Solían serlo los de ámbito local, pero también algunas de las más importantes casas. Por citar sólo algunas, que giraron bajo la sola firma del titular, al menos durante un cierto tiempo: Enrique Sainz, Tomás García Calamarte, Felipe Tutau, Alejandro Bacqué, Adolfo Bayo y Mariano Sabas Muniesa, en Madrid; Antonio Freixa, en Barcelona; Narciso Obanza, en La Coruña; y Pablo de Epalza y Andrés de Isasi, en Bilbao. Todas ellas eran casas de banca de primera magnitud.

ii) Sociedades colectivas._La evolución de las casas individuales podía dar lugar a la formación de sociedades colectivas. Por varios motivos, aunque todos ellos llevaban implicito un proceso de crecimiento. En ocasiones era la incorporación de hijos o parientes ( $« \mathrm{~J}$. Salzedo e Hijo», «Romualdo Céspedes y Sobrino»...); otras veces el fallecimiento del titular ( Hijos de Magín Valls», «Garriga Nogués Hnos.», «Vda. de Valle y Cía.»...) o la integración de los empleados como socios («Pedro Masaveu y Cía.»). Naturalmente, también había sociedades colectivas de nueva creación.

iii) Sociedades comanditarias.-Podían constituirse bajo esta fórmula por las razones anteriormente señaladas para las sociedades colectivas, pero con mayor frecuencia se formaban "en virtud de los resultados obtenidos por la sociedad y las probabilidades de adquirir mayor suma de beneficios ensanchando el círculo de operaciones» ${ }^{10}$. Con la forma comanditaria se hacía posible que personas que disponían de capital y no de conocimientos mercantiles, o bien que rehuían el riesgo que comportaba realizarlos como socios colectivos, pusieran esos recursos a disposición de quienes podían sacarles rendimiento. La forma comanditaria era la más frecuente en las casas que se formaban por unión de varios banqueros o comerciantes ( «P. Alfaro y Cía.», promovido por los Jover, Pascual Herrero y Mariano González Dueñas, bajo la gestión de Pelayo Alfaro; «Juliana y Cía.», constituida por las casas de banca Masaveu. Herrero y Alvaré; "Fabra Ponte y Cía.», apéndice bancario de los comerciantes de tejidos «Dotres, Clavé y Fabra»).

${ }^{10}$ De la escritura de constitución de uLlaguno, Morana, Ruiz y Cía., S. en C.», Madrid, 1884. 
Como en este trabajo se intenta demostrar que la calificación de banca tradicional era más bien de tipo formal, es preciso hacer una ligera reflexión al hablar de la forma jurídica que esta banca adoptaba. Como es sabido, los socios gerentes o colectivos estaban sometidos a una responsabilidad solidaria e ilimitada, lo que es una de las razones que se esgrimen para tildar a este tipo de sociedades de antiguas, tanto por el fuerte riesgo de la responsabilidad como la limitación de los capitales que podían reunir. Sin negarlo, es preciso no perder de vista que en esta época, con frecuentes quiebras que suponían la pérdida de una gran parte de los depósitos o los derecho contra los quebrados, la confianza que debía inspirar una institución bancaria se sustentaba sobre el «crédito» personal, razón por la que los banqueros debían comprometer $-o$, mejor dicho, su honorabilidad profesional les conducía a comprometer - no sólo su nombre, sino todos sus bienes.

No debe olvidarse tampoco un aspecto muy positivo en esta conformación tradicional, cual es la existencia de los socios industriales. Eran éstos unos socios que no aportaban capital alguno y sí su "pericia y laboriosidad", participando en la distribución de los beneficios pero no de las pérdidas, salvo que otra cosa se estipulase. Mediante este mecanismo, en las casas de comercio en general y, por tanto, también en las de banca, se fueron incorporando a las compañías los empleados que por su antigüedad y eficiencia habían dado muestras suficientes de dedicación y profesionalidad. Al acceder a esta categoría, se reconocía a los nuevos socios el derecho a participar en los beneficios (con frecuencia ya lo venían haciendo, aunque con una participación más baja), lo que producía un doble efecto: para el empleado, un decisivo estímulo en su promoción, ya que, de otro modo, difícilmente lograrían acumular una suma suficiente para participar como capitalista; para la empresa, la seguridad de que, al comprometerlos en la marcha del negocio, se aumentaba la productividad con la intensificación del esfuerzo y la dedicación. Este mecanismo, en mi opinión, ha sido insuficientemente valorado, y globalmente fue un factor de dinamización muy importante, en unos tiempos - no hay que olvidarlo- en que la mayoría de las empresas comerciales e idustriales se caracterizaban por unas dimensiones pequeñas y una estructura familiar o cuasi familiar. Los socios que habían ingresado como empleados eran, pues, casos frecuentes en las casas de comercio, y también en las de banca. Por poner un ejemplo de estas últimas, acudiremos a uno suficientemente elocuente, el de Luis de Ussía y Aldama, que después de haber sido empleado fue incorporado como socio co-administrador en la sociedad "Urquijo Hermanos», en 1880, sin aportar capital alguno, y tres años más tarde, con la ayuda del 15 por 100 de los beneficios con que era remunerado, pudo participar como socio gerente en la reconstitución de la misma casa, 
ahora denominada «Urquijo y Compañía», con el 30 por 100 del capital social ".

\section{El número de comerciantes-banqueros}

La abundancia numérica y dispersión espacial de los comerciantes-banqueros son argumentos de suficiente peso para probar su importancia. Para demostrarlo hay que desmontar previamente la confusión surgida del párrafo que Ramón Canosa dedica a los banqueros particulares en su libro Un siglo de banca privada, 1845-1945, y que ha sido utilizado tan frecuente como incorrectamente. Canosa afirma que "paralelamente existían banqueros particulares, reunidos como Sociedades de Seguros en el gremio oficial de comerciantes capitalistas, sujeto al llamado subsidio industrial, con una cuota de 8.000 rs. por agremiado. Esta cuota, desde 1857 hasta 1918 en que desapareció la organización gremial, tuvo las siguientes alternativas $(\ldots) \gg^{12}$, y relaciona en doble columna el número de agremiados y las cuotas correspondientes para una serie de años a partir de 1857. Este párrafo contiene, a mi juicio, varias inexactitudes, expresas o implícitas, que fueron motivo de interpretaciones desviadas que condujeron a conclusiones erróneas. Baso mi propuesta en los siguientes aspectos:

1. La organización gremial que agrupaba a los contribuyentes no nació en 1857, sino en 1847, por un Real Decreto firmado por el Ministro de Hacienda José de Salamanca, con fecha 3 de septiembre, en el que se establecía que «en cada población todos los individuos que ejerzan la misma industria, comercio o profesión (...) formarán gremio o colegio para el pago de la contribución industrial» ${ }^{13}$. En aplicación de este Decreto, el gremio que comprendía a quienes realizaban actividades de banca se denominó de «Banqueros o capitalistas negociantes que acumulan varias operaciones de crédito o de Bolsa, o que emplean habitualmente sus capitales en el giro o cambio de unas plazas a otras, préstamos a interés, seguros, descuentos, etc.», conservando, pues, la misma denominación establecida en la reforma de 1845 , y se fijaba una cuota dividida en seis clases, que oscilaba entre los 8.000 reales para los establecidos en Madrid y los 460 reales para los de pueblos, con cuatro clases intermedias para las diferentes ciudades. El modelo era, por tanto, más complejo que el recogido por Canosa, y desde luego la actividad bancaria presentaba una entidad propia y distinta de las sociedades de seguros.

"Escrituras de 30 junio 1880 y 10 enero 1883, not. Juan Zozaya, prot. 35142, AHPM.

12 R. Canosa (1945), p. 39.

13 Real Decreto 3-9-1847, CLE, T-42, p. 28. 
2." El gremio, que como acabamos de ver, empezó siendo de «banqueros o capitalistas negociantes", cambió de definición y, por tanto, de contenido, en una posterior alteración de la normativa fiscal, vigente sólo durante el período 1853-1869, en que pasó a denominarse de «Comerciantes o capitalistas negociantes que reciben o remiten, compran o venden por su cuenta o en comisión productos del país, géneros extranjeros o coloniales, tengan o no consignaciones y mercaderías para su distribución y venta, bien que se limiten a hacer operaciones de banca, giro, descuento o seguros" ${ }^{14}$. En este breve intervalo de tiempo quedaron adscritos a él comerciantes diversos, tanto los que realizaban como los que no efectuaban operaciones de banca. Por este motivo, el número de agremiados en el período 1853.1869 no nos sirve para conocer los que ejercían la «industria de banca».

3. Lo más importante quizá, que también ha sido erróneamente interpretado, es que los gremios eran agrupaciones locales, «de los que en cada población» ejercían la misma industria o comercio, por lo que las cifras de agremiados que da Canosa corresponden sólo a los matriculados en Madrid, lo que se comprueba, además, porque la cuota que cita de 8.000 reales es precisamente la que se aplicaba a los establecidos en Madrid (aunque luego habría de repartirse en proporción a la importancia de cada agremiado entre los límites del cuádruplo y la cuarta parte).

Hechas estas precisiones, veamos ahora la posibilidad de conocer el número de banqueros y comerciantes banqueros operantes en España. Disponemos para ello de la Estadística administrativa de la Contribución indus. trial y de comercio, elaborada por el Ministerio de Hacienda, que enumera los contribuyentes por cada epígrafe agrupados por provincias. Según esta Estadística... (véase el cuadro 2) el número de comerciantes-banqueros matriculados aumentó sensiblemente en la segunda mitad del siglo xIX, lo que invalida la pretendida disminución de los banqueros particulares, disminución que, sin embargo, puede ser cierta para algún caso concreto, por ejemplo Madrid, que presenta una notable reducción en los años ochenta para luego mantenerse prácticamente estable hasta fin de siglo. Pero, salvo excepciones, en la mayor parte de las provincias el aumento fue la norma general, y en algunas, caso de Alicante, Barcelona, Cádiz, Gerona, Murcia, Oviedo y Sevilla, el incremento fue muy fuerte. En definitiva, el número de comerciantes banqueros matriculados pasó de 150 en 1879 a 239 en 1900 (al que habría que añadir los de las provincias exentas, Alava, Guipúzcoa, Vizcaya y $\mathrm{Na}$ varra), crecimiento importante, como no podía ser de otra manera, acompañando la evolución del comercio y la industria y la carencia de bancos.

\footnotetext{
" RD 20-10-1852, Gaceta de Madrid, 25-10-1852.
} 


\section{CUADRO 2}

Comerciantes-banqueros matriculados en la Contribución Industrial

\begin{tabular}{|c|c|c|c|c|c|c|}
\hline Provincias & 1879 & $\begin{array}{l}1889- \\
1890\end{array}$ & $\begin{array}{l}1893- \\
1894\end{array}$ & $\begin{array}{l}1895 \\
1896\end{array}$ & 1900 & 1897 \\
\hline Albacete $\ldots \ldots \ldots$ & - & - & 1 & 1 & 3 & 1 \\
\hline $\begin{array}{llll}\text { Alicante } & \ldots & \ldots & \ldots\end{array}$ & - & 5 & 13 & 6 & 13 & 23 \\
\hline $\begin{array}{cccc}\text { Almería } & \ldots & \ldots & \ldots\end{array}$ & - & - & 7 & - & - & 24 \\
\hline Avila $\ldots \ldots \ldots \ldots$ & - & 3 & 2 & 3 & 4 & 1 \\
\hline $\begin{array}{cccc}\text { Badajoz } & \ldots & \ldots & \ldots\end{array}$ & 5 & 10 & 9 & 6 & 6 & 15 \\
\hline Barcelona . ... ... & 8 & 18 & 34 & 23 & 27 & 32 \\
\hline Burgos .... ... ... & - & 4 & 4 & 4 & 3 & 8 \\
\hline $\begin{array}{llll}\text { Cáceres } & \ldots & \ldots & \ldots\end{array}$ & - & 1 & - & - & 4 & 9 \\
\hline $\begin{array}{ccccc}\text { Cádiz } & \ldots & \ldots & \ldots & \ldots\end{array}$ & 7 & 9 & 14 & 13 & 17 & 21 \\
\hline Castellón .......... & - & 4 & 4 & 1 & 2 & 5 \\
\hline C. Real $\ldots \ldots$. & 1 & 2 & 2 & 2 & 3 & 17 \\
\hline $\begin{array}{llll}\text { Córdoba } & \ldots & \ldots & \ldots\end{array}$ & 3 & 3 & 3 & 2 & 2 & 14 \\
\hline $\begin{array}{lllll}\text { Coruña } & \ldots & \ldots & \ldots\end{array}$ & 1 & 2 & 2 & 2 & 3 & 20 \\
\hline $\begin{array}{llll}\text { Cuenca } & \ldots & \ldots & \ldots\end{array}$ & - & - & 0 & - & - & 4 \\
\hline $\begin{array}{llll}\text { Gerona } & \ldots & \ldots & \ldots\end{array}$ & 8 & 9 & 20 & 17 & 19 & 17 \\
\hline $\begin{array}{llll}\text { Granada } & \ldots & \ldots & \ldots\end{array}$ & 9 & 4 & 4 & 3 & 4 & 6 \\
\hline Guadalajara $\ldots \ldots$ & - & - & - & 1 & - & 2 \\
\hline $\begin{array}{lllll}\text { Huelva } & \ldots & \ldots & \ldots\end{array}$ & 2 & 1 & 3 & 2 & 6 & 19 \\
\hline $\begin{array}{lllll}\text { Huesca } & \ldots & \ldots & \ldots\end{array}$ & 1 & 2 & 2 & 1 & 3 & 11 \\
\hline $\begin{array}{llllll}\text { Jaén } & \ldots & \ldots & \ldots & \ldots\end{array}$ & 8 & 5 & 7 & 6 & 6 & 15 \\
\hline León $\ldots \ldots \ldots \ldots$ & 7 & 3 & 2 & 2 & 2 & 5 \\
\hline $\begin{array}{llll}\text { Lérida } & \ldots & \ldots & \ldots\end{array}$ & 3 & 2 & 2 & 4 & 2 & 6 \\
\hline $\begin{array}{llll}\text { Logroño } & \ldots & \ldots & \ldots\end{array}$ & 1 & 4 & 5 & 4 & 3 & 5 \\
\hline $\begin{array}{llllll} & \text { Lugo } & \ldots & \ldots & \ldots & \ldots\end{array}$ & 1 & - & 1 & 1 & 1 & 3 \\
\hline Madrid $\ldots \ldots \ldots$ & 42 & 31 & 31 & 30 & 29 & 36 \\
\hline $\begin{array}{lllll}\text { Málaga } & \ldots & \ldots & \ldots\end{array}$ & 2 & - & 2 & 2 & 4 & 20 \\
\hline $\begin{array}{llll}\text { Murcia } & \ldots & \ldots & \ldots\end{array}$ & 3 & 5 & 7 & 5 & 10 & 24 \\
\hline Orense $\ldots \ldots \ldots$ & - & 1 & 2 & 1 & 4 & 2 \\
\hline $\begin{array}{lllll}\text { Oviedo } & \ldots & \ldots & \ldots\end{array}$ & 2 & 5 & 7 & 8 & 13 & 15 \\
\hline $\begin{array}{lllll}\text { Palencia } & \ldots & \ldots & \ldots\end{array}$ & 1 & - & 2 & - & 2 & 3 \\
\hline $\begin{array}{lll}\text { Pontevedra } & \ldots & \ldots\end{array}$ & - & 一 & - & 2 & 1 & 15 \\
\hline Salamanca . ... ... & 2 & 3 & 1 & 1 & 1 & 6 \\
\hline Santander $\ldots \ldots$ & - & 1 & 3 & 3 & 3 & 5 \\
\hline $\begin{array}{lllll}\text { Segovia } & \ldots & \ldots & \ldots\end{array}$ & - & 2 & 1 & - & 2 & 1 \\
\hline Sevilla.$\ldots \ldots \ldots$ & - & 4 & 2 & 2 & 8 & 13 \\
\hline
\end{tabular}

Banqueros según el Anuario

Bailly-Bailliere 


\section{CUADRO 2 (Continuación)}

\section{Comerciantes-banqueros matriculados en la Contribución Industrial}

\begin{tabular}{|c|c|c|c|c|c|c|}
\hline Provincias & 1879 & $\begin{array}{l}1889 . \\
1890\end{array}$ & $\begin{array}{l}1893 . \\
1894\end{array}$ & $\begin{array}{l}1895- \\
1896\end{array}$ & 1900 & 1897 \\
\hline $\begin{array}{lllll}\text { Soria } & \ldots & \ldots & \ldots & \ldots\end{array}$ & 1 & 2 & - & 2 & 1 & 2 \\
\hline Tarragona . ... ... & 2 & 1 & - & - & - & 5 \\
\hline Teruel $\ldots \ldots \ldots$ & 5 & - & - & 5 & 5 & 5 \\
\hline $\begin{array}{llll}\text { Toledo } & \ldots & \ldots & \ldots\end{array}$ & 2 & - & 2 & 1 & 3 & 6 \\
\hline $\begin{array}{lllll}\text { Valencia } & \ldots & \ldots & \ldots\end{array}$ & 9 & 5 & 6 & 8 & 6 & 24 \\
\hline Valladolid . ... ... & 4 & 5 & 3 & 3 & 2 & 8 \\
\hline $\begin{array}{lllll}\text { Zamora } & \ldots & \ldots & \ldots\end{array}$ & - & 2 & - & - & 1 & 4 \\
\hline Zaragoza ... ... ... & 7 & 8 & 7 & 5 & 7 & 13 \\
\hline $\begin{array}{lllll}\text { Baleares } \ldots & \ldots & \ldots\end{array}$ & 3 & 3 & 3 & 2 & 1 & 11 \\
\hline $\begin{array}{llll}\text { Canarias } & \ldots & \ldots & \ldots\end{array}$ & - & - & 3 & 2 & 3 & 12 \\
\hline \multirow[t]{2}{*}{ Totales } & 150 & 169 & 223 & 186 & 239 & $\begin{array}{l}2 \text { Alava } \\
6 \text { Guipúzcoa } \\
8 \text { Vizcaya } \\
9 \text { Navarra }\end{array}$ \\
\hline & & & & TOTAL & $\ldots \ldots$ & 538 \\
\hline
\end{tabular}

Fuentes: Estadistica administrativa de la Contribución Industrial y de Comercio y Anuario del Comercio... Bailly-Bailliere (1897).

Pero con ser importante el aumento registrado en la Estadística..., en la realidad debió de ser mucho mayor, pues los pequeños comerciantesbanqueros, especialmente los establecidos en poblaciones pequeñas, se resistían a darse de alta en la matrícula fiscal, que les resultaba excesivamente onerosa en comparación con los beneficios que les reportaban muchas de las operaciones de banca, no estando, por tanto, computados estadísticamente. Sí lo estaban, con toda probabilidad, las casas más importantes, que por su volumen de negocio no podían ocultarse ni del fisco ni de sus propios colegas agremiados.

Como contrapunto de la estadística oficial, y para establecer una comparación, podemos servirnos de las guías y anuarios que relacionaban a todos los comerciantes y profesionales agrupados por actividades. Entre ellos figu- 
raban los dedicados a actividades bancarias, bancos y banqueros. Utilizando esta fuente hemos añadido al cuadro 2 una columna suplementaria, que nos permite ver cómo las casas de banca relacionadas en estos anuarios suponían más del doble de los matriculados fiscalmente como tales. En algunos casos, la diferencia no es muy grande - caso de Madrid, Barcelona, Cádiz, Gerona, Oviedo- en lo que tendría que ver la importancia de las casas y la eficacia de los servicios de inspección de la Hacienda, pero en otros resulta espectacular: para Almería, sin banqueros matriculados, aparecen relacionados 24; en La Coruña, 2 matriculados y 20 relacionados; en Huelva, 2 matriculados y 19 relacionados; en Málaga, 2 matriculados y 20 relacionados; en Pontevedra, 2 matriculados y 15 relacionados, y en Valencia, 8 matriculados y 24 relacionados.

De las dimensiones y volumen de negocio de las casas relacionadas en los anuarios poco se puede decir, al no disponer de información directa. Probablemente una gran parte de ellas, sobre todo las localizadas en los pueblos, eran todavía más comerciantes que banqueros, en el sentido de dedicarse aún preferentemente al comercio de mercancías, pero esto no les resta valor para los fines que aquí nos interesan: demostrar la existencia de una oferta de servicios bancarios.

Que las guias y anuarios contienen o pueden contener inexactitudes nadie lo pone en duda. Pero quizá las tengan más por defecto que por exceso. Desde luego, en los casos en que disponemos de un conocimiento más preciso y documentado, así sucede. Veamos, por ejemplo, el caso de Asturias. En la Estadistica... figuran 8 comerciantes-banqueros matriculados en 1896, y 13 en 1900, mientras en el anuario del que se extrajo la información que venimos manejando se relacionan 15 . No obstante, investigaciones propias en fuentes documentales ${ }^{15}$ permiten localizar algunos más, como se advierte en el cuadro 3.

Para contribuir a un mejor conocimeinto de estos comerciantes-banqueros, personajes semiocultos pero perfectamente reales, podría resultar de interés conocer algunos nombres, el quién es quien de la banca del ochocientos. Como resultaría excesivamente extenso relacionar todos los conocidos para tan larga época, vamos a limitarlo a algunas plazas importantes y a los años finales de siglo, que es para cuando erróneamente se ha venido afirmando que prácticamente habían desaparecido.

Así, pues, está fuera de toda duda la expansión numérica de los comerciantes-banqueros, que a finales de siglo multiplicaban con gran amplitud al conjunto de establecimientos bancarios con forma de sociedad anónima. ¿Puede seguirse de esta comparación alguna conclusión? Desde luego, aun

${ }^{15}$ J. R. García López (1987). 


\section{CUADRO 3}

\section{Comerciantes-banqueros establecidos en Asturias (año 1897)}

J. Alvaré y Cía. (Oviedo)

Herrero y Cía. (Oviedo)

Masaveu y Cía. (Oviedo)

Vda. de Prado y Cía. (Oviedo)

Hijos de González Alegre (Oviedo)

Luis Belaúnde (Gijón)

Florencio Rodríguez (Gijón)

Velasco y Cía. (Gijón)

Junco y Ruisánchez (Cangas de Onís)

José Pallarés (Cangas de Tíneo)

Maribona y Hno. (Avilés)

Pablo Pérez e Hijos (Colunga)

Braulio Vigón (Colunga)

Ramón G. Carbajal (Infiesto)
Víctor Fernández Caunedo (Luarca)

Vicente Trelles (Luarca)

Bruno García (Llanes)

Vda. e Hijos de R. Sobrado (Llanes)

Gregorio Vigil Escalera (P. de Siero)

Blanco Hermanos (Ribadesella)

Salvador Fernández (Pravia)

Laureano Pérez Villamil (Pto. de Vega)

Ramón López (Trubia)

Vicente Velarde (Salas)

Luis Sela (Santullano)

Pedro Cotarelo (Vegadeo)

Francisco Zaldívar (Villaviciosa)

Fuente: Libros de cuentas de banqueros asturianos. Véase J. R. Garcia López (1987).

\section{CUADRO 4}

\section{Banqueros establecidos en Madrid (año 1897)}

P. Alfaro y Cía.

Alejandro Bacqué

Ignacio Baüer e Hijo

Adolfo Bayo y Bayo

Cabanellas Hnos.

Sobrinos de Céspedes

Leopoldo Collado

Jerónimo Corrales y Hno.

Luis Fernández de Heredia

Garcia Calamarte e Hijo

José González del Valle

José Remigio González

Antonio Herrero

Carlos Jiménez
Max. Laffitte y Cía.
Rodulfo León
Simón López y Hno.
Llaguno y Cía.
Marqués de Casa-Loring
Miqucletorena e Hijos
Francisco Morana
Vda. e Hijos A. G. Moreno
Javier Muguiro
Juan J. de Oñativia
Rodríguez Hermanos

F. Palomar y Cía.

G. Rolland, Hijo

Luis Rov, Sobrino

Mariano Sabas Muniesa

E. Sainz e Hijos

J. Salzedo, Hijo, y Cía.

Rafael San José

Sbarbi, Osuna y Cía.

Urquijo y Compañia

Guillermo Vogel y Cía.

Vda. e Hijos de S. Velasco

Zúñiga Hermanos

Fuentes: Anuario de la Bolsa (1897) y Anuario del Comercio Bailly-Bailliere (1897). 


\section{CUADRO 5}

Banqueros establecidos en Barcelona (año 1897)

\author{
Cayetano Roger \\ Roura y Compañia \\ Vidal Quadras Hnos. \\ José Casals (Canet de Mar) \\ Puig y Humbert (Canet de Mar) \\ Lorenzo Obiols (Berga) \\ Ramón Pujol (Berga) \\ Salvador Valls (Granollers) \\ Buenaventura Catarineu (Igualada) \\ José Ferrer Llopart (Igualada) \\ Francisco Oller (Manresa) \\ Onofre Serra (Manresa) \\ Raurich y Cía. (Manresa) \\ Sebastián Prat (Malgrat) \\ Joaquín Pagés (Sabadell) \\ Hijo de Buenaventura Marcet (Tarrasa) \\ Molas, Ricart y Cía. (Vich) \\ Miguel Trías (Vich)
}

FuEntes: Anuario de la Bolsa (1897) y Anuario del Comercio Bailly-Bailliere (1897).

\section{CUADRO 6}

Banqueros establecidos en La Coruña (año 1897)

Vda. e Hijos de Atocha

Eusebio Guarda

Guyatt y Bowstron

Herce y Cía.

López Trigo Hnos.

Hijos de Marchesi

Maristain Hnos.

Narciso Obanza

Sobrinos de J. Pastor

Peña y Compañía
Hijos de J. Pérez, López y Cía.

Presas y Cía.

Eduardo del Río

Rubine e Hijos

Nicolás Soler

Ramón Blanco (Ortigueira)

Crisanto Armada (Ortigueira)

Hijos de Pérez Sáenz (Santiago)

Lorenzo López de Riego (Santiago)

Vda. e Hijcs de Simeón García (Santiago)

Fuente: Anuario del Comercio Bailly-Bailliere (1897). 
considerando solamente el número de banqueros matriculados, que correspondería a los más importantes, resultaría muy aventurado proponer que al ser más del doble que el número de bancos, también era doble su peso en conjunto, porque se alegará - y con razón- que entre los banqueros matriculados los había de poca entidad. Eso es tan cierto como que también entre los bancos había algunos con un funcionamiento tan lánguido que su volumen de operaciones era reducidísimo. Por eso habremos de posponer esta comparación hasta que se pueda efectuar sobre cifras concretas. Lo que sí es innegable es que el colectivo de comerciantes-banqueros, aun adoleciendo también de cierta polarización en Madrid y Barcelona, presentaba a fines del siglo xIx una dispersión geográfica que cubría todo el territorio español, con especial intensidad en las provincias costeras y los núcleos industriales.

\section{Eficiencia organizativa y funcional}

Después de haber comprobado la abundancia numérica, la segunda razón que estimo decisiva para demostrar la importancia de los comerciantesbanqueros es su eficiencia, que se manifestaba, de cara al exterior, en la eficaz prestación de los servicios de intermediación financiera requeridos a las instituciones bancarias, y de puertas adentro, en la obtención de unos excelentes resultados. Una vez más, hay que preguntarse si pudieron estas empresas de «tipo antiguo» competir en costos y prestaciones con los bancos. $\mathrm{Y}$ nuevamente la respuesta debe ser, a mi juicio, afirmativa. Para constatarla, veamos cuáles eran los medios que ambos tipos de instituciones tenían a su disposición, y las ventajas e inconvenientes que se derivaban de su estructura.

No había diferencias en cuanto a la técnica. Unos y otros empleaban los mismos sistemas amanuenses en la contabilidad, correspondencia y demás operaciones de administración, lo que ahora se llaman los «costos de transformación». Quizá la única innovación significativa fue la aportada por el Banco de España, cuando en 1884 -nótese lo avanzado de la fecha- instauró el servicio de transferencias gratuitas entre cuentas de sus sucursales. Pero esto sólo lo podía hacer el Banco de España, porque los bancos privados, casi en su totalidad, disponían de una sola oficina, como los comerciantesbanqueros, precisando de corresponsales para sus relaciones con otras plazas.

Tampoco había diferencias en el tipo de operaciones y servicios, ya que los comerciantes-banqueros realizaban «toda clase de negocios y comisiones bancarias», cubriendo los tres niveles que J. Bouvier (1981) señala para el 
conjunto de la oferta bancaria: provisión de medios de pago, de medios de financiación y de servicios diversos ${ }^{16}$.

Es posible que la única diferencia favorable a los bancos fuese de escala. La disponibilidad de mayores capitales pudo permitir, en principio, la realización de mayores operaciones de préstamos o compromisos con grandes proyectos. En este sentido, hay que pensar especialmente en la financiación de los tendidos ferroviarios, cuestión que, por otra parte, ha recibido fuertes críticas de los historiadores, al estimar que supuso una excesiva concentración de riesgo, al tiempo que dejó desasistida a la industria. Con relación a la industria, sin embargo, es discutible que los bancos hayan tenido más influencia que los comerciantes-banqueros. Cameron pone de relieve cómo en las primeras etapas de la industrialización — que podía definir la situación española del ochocientos- las firmas industriales no son de grandes proporciones y resuelven su crecimiento de capital fijo mediante la reinversión de beneficios, autofinanciación que se hace posible gracias a la financiación de capital circulante por las instituciones bancarias ${ }^{17}$. Precisamente fue ésta una función realizada muy eficazmente por los comerciantes-banqueros, que auxiliaban a la industria de varias maneras: facilitando cobros y pagos con el exterior mediante el giro, la negociación y el descuento de efectos; suministrando una parte del capital circulante mediante créditos a corto plazo (que a veces se convertían en largo plazo por renovaciones sucesivas) y descubiertos en cuenta corriente (en realidad créditos sin formalizar); y, finalmente, haciendo las funciones de cajeros, es decir, poniendo a su disposición las sumas de efectivo necesarias. Y no se diga que este esquema era sólo válido para las regiones donde la industria era ligera y no necesitaba grandes inversiones, porque el prototipo de industria pesada, la siderurgia moderna (definida por altos hornos alimentados por carbón de cok), surgió en Asturias en los años cincuenta, siendo sus principales firmas «A. E. Marteville y Cía.», «Gil y Cía.», "Duro y Cía.», auxiliadas de manera determinante por los comerciantesbanqueros asturianos ${ }^{18}$.

10 Véanse J. Bouvier (1981) y J. R. García López (1985). En este trabajo se analiza la actuación de los comerciantes-banqueros en los tres niveles citados.

${ }^{17}$ R. Cameron (1974), pp. $52-56$ y 68-70.

1* En 1866, la empresa siderúrgica ubicada en La Rebollada (Mieres), "A. E. Marteville y Cía.», y la casa de banca ovetense «Herrero y Compañía», «que ha venido hasta la fecha desempeñando el cargo de banca» de la primera, suscriben un contrato para el descuento de papel hasta noventa días por importe de 200.000 pesetas (Esc. 10-7-1866, not. J. Rodríguez, prot. 1625, AHPO). Al constituirse la empresa siderúrgica "Gil y Compañía” (1857), de la que sería director el que también lo era de la Fábrica de Armas de Trubia, Antonio Elorza, uno de los promotores, y socio gereńte, Casimiro Domínguez Gil, que realizaba actividades de banca en Gijón, donde residía, se le reconoce cstatutariamente que "será a la vez Cajero y facilitará los fondos mediante una comisión de $1 / 2 \% \ldots$.. (Esc. 20-5-1857, not. León Muñoz, prot. 26258, AHPM). La casa «Pedro Masaveu y Cía.», de Oviedo, a lo largo del último cuarto de siglo descuenta papel a las más importantes 
Más claras y significativas eran las ventajas a favor de los comerciantesbanquęros. derivadas de su „orooia estructurą organizativa v funcional. Gozaban de una mayor agilidad operativa, con personal cualificado y unos gestores directamente comprometidos en la marcha del negocio (compromiso que incluía todos sus bienes). A ello se unía una larga tradición en los negocios, que si por un lado les aportaba una gran profesionalidad, también les otorgaba una respetabilidad a la que los negocios bancarios - y más los de esa época- son tan sensibles. Otra ventaja importante, importancia que se hizo notar hasta fines de siglo, provenía del carácter mixto del negocio - comercio de mercancías y banca- que hacía posible que las funciones administrativas, de escritorio, fuesen comunes, lo que permitía diluir los gastos de administración, cuestión no desdeñable en una actividad que obligaba a trabajar con unas comisiones bajísimas. Esto no sólo daba ventaja a los comerciantesbanqueros (entendidos en este caso como los que simultaneaban comercio de mercancías y banca) sobre los bancos, cuya pesada estructura - Comisario Regio, Consejo de Administración, Dirección- gravaba sus costos, sino también sobre los que eran estrictamente banqueros, es decir, los que no realizaban compraventa de mercancías.

Todas las ventajas que poseían los comerciantes-banqueros sobre los bancos se traducían en la obtención de mayores beneficios en relación al capital invertido, y no son otra cosa que la expresión de una elevada rentabilidad obtenida por una mejor —o al menos más congruente y adaptada a su entorno- estructura de funcionamiento, dimensión y organización. La consecuencia lógica fue un notorio crecimiento de estas casas de banca, tanto en número como en importancia individual.

Veamos ahora algún ejemplo concreto que refuerce los anteriores argumentos. Disponemos de uno suficientemente expresivo. Se trata de un caso que permite conocer las actitudes de un banco (el Banco de Oviedo) y de un comerciante-banquero (Enrique Sainz, de Madrid) ante un problema semejante.

El Banco de Oviedo, banco emisor fundado en mayo de 1864 , se vio afectado a finales de ese mismo año por la caótica situación que atravesaba la plaza de Valladolid. En su cartera tenía diversos pagarés suscritos por comerciantes relacionados con dicha plaza que, afectados por las múltiples quiebras y suspensiones de pagos, terminaron en la misma situación. Sumaban en junto los efectos fallidos 366.000 pesetas, que equivalía a un 16

industrias asturianas (Real Compañia Asturiana de Minas, Ferrocarril de Langreo, Sociedad de Explosivos de la Manjoya, Cía. de los Ferrocarriles Económicos...), pero de especial relevancia por su magnitud es la relación con «Fábrica de Mieres, S. A.», a la que mantiene desde 1888 un crédito a largo plazo (aunque sin formalizar) por un importe superior al millón de pesetas (J. R. García López, 1988, pp. 147.153). 
por 100 del activo ${ }^{19}$, lo que le supuso un duro golpe que le conduciría a arrastrar una vida lánguida hasta su fusión con el Banco de España en 1874. Cuando esta fusión se lleva a cabo, todavía figuraban en su balance, bajo el eufemismo de «Cobros pendientes» —en realidad absolutamente incobrables-, las tres cuartas partes de los pagarés protestados nueve años antes. Había empezado a amortizarlos cinco años después de haberse producido, y nueve años más tarde sólo había conseguido amortizar el 20 por 100.

El otro punto de comparación es el de la Casa Sainz, de Madrid. Enrique Sainz del Rivero, antiguo apoderado de la casa «Viuda de Lavín», había abierto en 1856 bajo su sola firma una casa de banca continuadora de aqué1la. Las tensiones monetarias generadas por la falta de numerario y la espiral de desconfianza que se desencadenó en 1864-65 produjeron una serie de quiebras y suspensiones de pagos en cadena, alguna de las cuales alcanzó a casas de las que Enrique Sainz era acreedor por sumas importantes: la «Compañía General de Crédito en España", con 170.000 pesetas; Luis Guilhou, con 102.000 pesetas; Manuel Sáenz de Tejada (Cádiz), con 130.000 pesetas, y otros varios por importes menores hasta totalizar 483.000 pesetas. Suponía esta suma más del 30 por 100 del activo de la Casa Sainz, lo que muestra bien claramente la extrema gravedad de tales fallidos, de los que solamente recuperaría poco más de la tercera parte. Ante tamaña catástrofe, esta casa, de modo inmediato, procede a amortizar la suma irrecuperable en anualidades con cargo a los resultados de cada ejercicio, de modo que unos años más tarde la pérdida prácticamente había sido absorbida, quedando el Activo completamente saneado ${ }^{20}$.

Vistas las disposiciones adoptadas por el banco y el banquero, cabe ahora hacer la comparación y preguntarse cuál de las dos instituciones bancarias empleó criterios de modernidad y eficacia. Desde luego, quizá la política de amortizaciones sea la mejor piedra de toque para calificar una actuación empresarial, y el ejemplo nos muestra una institución moderna, el Banco de Oviedo, anquilosada e incapaz de recuperarse, arrastrando un activo ficticio, mientras la institución antigua, el comerciante-banquero Enrique Sainz, procede a digerir el pesadísimo quebranto prosiguiendo su expansión una vez liberado de ese lastre. Naturalmente, ello fue posible por dos circunstancias diferenciadoras: la capacidad de generar beneficios y la ausencia de una política de dividendos. En ambas cuestiones fue manifiesta la posición ventajosa que definía la configuración de los negocios del comerciante-banquero, confirmando lo dicho acerca de su eficiencia operativa y funcional.

19 Libros Mayor y de Inventarios del Banco de Oviedo.

${ }^{20}$ Libro de Inventarios de Enrique Sainz (Madrid). 


\section{Conclusiones}

Como resumen de lo expuesto, podemos concluir constatando que el sistema bancario español del siglo XIX se caracterizó por una estructura dual, si por ello entendemos la coexistencia de instituciones con formas antiguas (pero con usos y técnicas modernas), junto con formas nuevas (bancos). La modernización del sistema bancario, entendida como formación de bancossociedad anónima, intentada entre 1856 y 1881 , fracasó, posponiéndose hasta los años veinte de nuestro siglo, en que los bancos pudieron disponer áe mejores medios técnicos y amplias redes de sucursales, que les otorgaron las ventajas decisivas. Entre tanto, durante la segunda mitad del siglo XIX, con los escascs efectivos modernos supervivientes, proliferaron los comerciantesbanqueros y casas de banca de tipo antiguo, que perfeccionaron sus técnicas, ampliaron sus negocios y crecieron tanto individual como colectivamente hasta dar lugar a una tupida y eficaz red - sistema - bancaria, que cubrió los servicios que la banca moderna no pudo atender.

Estos comerciantes-banqueros demostraron adaptarse mejor a las condiciones de su época. Para ello contaron a su favor con una estructura más simple y ágil, de menores costos, que unido a una gran experiencia y profesionalidad les supuso una elevada eficiencia que se tradujo en claras ventajas operativas. La gran mayoría de estas casas de banca no desapareció por decadencia, falta de operaciones o malos resultados, sino que su propio dinamismo les condujo a transformarse o integrarse en sociedades anónimas cuando el momento fue propicio, con una etapa de transición que ocupó las primeras décadas de nuestro siglo.

Detrás de estos dos tipos de instituciones bancarias, «antiguas y modernas", no se encontraban dos tipos distintos de personas con mentalidades antagónicas, sino que con frecuencia los que encabezaron las primeras, promovieron las segundas. Muchos de los comerciantes-banqueros figuraron entre los promotores o consejeros de casi todos los bancos que se constituyeron al amparo de la ley de 1856, y muchos también prestaron su concurso y sus capitales en la constitución de empresas en los sectores más progresivos de la industria del último cuarto de siglo —compañías eléctricas, navieras, químicas, cementeras, azucareras, etc.--, demostrando con ello estar en una línea de progreso y modernidad.

En definitiva, en la segunda mitad del siglo xIx fracasaron los intentos de modernizar el sistema bancario español (en el sentido formal expuesto), pero no por ello el país careció de los servicios bancarios esenciales. Quizá no había llegado la hora de los bancos, y éstos resultaban anacrónicos en el conjunto de la atrasada sociedad española, o quizá fueron enfocados con desmedidos afanes especulativos. En cualquier caso, otras instituciones desempe- 
ñaron eficazmente las funciones requeridas por una economía en crecimiento: los comerciantes-banqueros, cuya existencia numerosa y eficiente, imprescindible para explicar la historia bancaria del ochocientos, ha sido el objetivo de este trabajo.

\section{BIBLIOGRAFIA}

Anes Alvarez, Rafael (1974): «El Banco de España (1874-1914): un banco nacional», en La Banca española en la Restauración, I, Madrid, Servicio de Estudios del Banco de España.

BOUVIER, Jean (1981): «Relaciones entre sistemas bancarios y empresas industriales en el crecimiento europeo del siglo xIX», en La industrialización europea, Barcelona, Crítica, pp. $135-172$.

CAMERon, Rondo (1974): La banca en las primeras elapas de la industrialización, Ma. drid, Tecnos.

Canosa, Ramón (1945): Un siglo de banca privada, 1845-1945, Madrid, Nuevas Gráficas.

GARCíA LóPEz, José Ramón (1985): «Banqueros y comerciantes-banqueros, clave oculta del funcionamiento del sistema bancario español del siglo XIX", Moneda y Crédito, núm. 175 , diciembre, pp. 59.85 .

- (1987): Los comercianies-banqueros en el sislema bancario español. Estudios de casas de banca asturianas en el siglo XIX, Universidad de Oviedo.

- (1988): «Las relaciones banca-industria en el siglo XIX. Banqueros y comerciantesbanqueros en la industrialización asturiana», en La industrialización del norte de España, Barcelona, Crítica, pp. 147.153.

Nadal Oller, Jordi (1987): «La industria fabril española en 1900. Una aproximación», en La economia española en el siglo XX. Una perspectiva bistórica, Barcelona, Ariel, pp. 23-61.

Orazu, Alfonso (1988): Los Rotbschild y sus socios en España, 1820-1850, Madrid, O. Hs. Ediciones.

SÁNCHEZ-AlboRnoz, Nicolás (1968): España bace un siglo: una economia dual, Madrid, Alianza.

TEDDE DE LORCA, Pedro (1974): «La banca privada española durante la Restauración, 1874-1914», en La Banca española en la Restauración, I, Madrid, Servicio de Estudios del Banco de España.

- (1983): «Comerciantes y banqueros madrileños al final del Antiguo Régimen», en Historia económica y pensamiento social, Madrid, Alianza.

Tortella Casares, Gabriel (1975): Los origenes del capilalismo en España, Madrid, Tecnos. 